\title{
DEVELOPMENT AND PHYSICOCHEMICAL CHARACTERIZATION OF DEXAMETHASONE-LOADED POLYMERIC NANOCAPSULE SUSPENSIONS
}

Rossana Barcellos Friedrich, Marcia Camponogara Fontana and Ruy Carlos R. Beck*

Departamento de Farmácia Industrial, Universidade Federal de Santa Maria, 97105-900 Santa Maria - RS, Brasil

Adriana Raffin Pohlmann

Departamento de Química Orgânica, Instituto de Química, Universidade Federal do Rio Grande do Sul, 91501-970 Porto

Alegre - RS, Brasil

Silvia Stanisçuaski Guterres

Faculdade de Farmácia, Universidade Federal do Rio Grande do Sul, 90610-000 Porto Alegre - RS, Brasil

Recebido em 5/7/07; aceito em 11/10/07; publicado na web em 2/4/08

\begin{abstract}
The influence of drug concentration, oil phase, and surfactants on the characteristics of dexamethasone-loaded nanocapsules was investigated. The best formulations were obtained at dexamethasone concentrations of 0.25 and $0.50 \mathrm{mg} \cdot \mathrm{mL}^{-1}$ (encapsulation efficiency: $80-90 \%$; mean size: $189-253 \mathrm{~nm}$ ). The type of oil phase influenced only the stability of dexamethasone-loaded nanocapsules. The association of polysorbate 80 and sorbitan monooleate provided a more stable formulation. Sunflower oil and sorbitan sesquioleate used for the first time as oil phase and surfactant for nanocapsules, respectively, have allowed obtaining suspensions with low mean size and narrow size distribution.
\end{abstract}

Keywords: dexamethasone; nanocapsules; nanoparticles.

\section{INTRODUCTION}

Dexamethasone is a poor-water soluble glucocorticoid that is used clinically as an anti-inflammatory and immunosuppressive agent. However, its use is often restricted by the induction of some side effects (hypertension, peptic ulcers, hyperglycemia and hydroelectrolytic disorders) mainly when administered by systemic route. ${ }^{1}$ Topical administration of dexamethasone is clinically used for the treatment of many ocular disorders, or diseases, like uveitis, ${ }^{2}$ allergic conjunctivitis, ${ }^{3}$ corneal postoperative period, ${ }^{4}$ as well as for the treatment of skin disorders such as atopic dermatitis, ${ }^{5,6}$ allergic dermatitis, eczematous dermatitis, ${ }^{6,7}$ psoriasis, acne rosacea, ${ }^{8}$ and phimosis. ${ }^{9}$

Over the last years many efforts have been made not only to improve the efficacy and bioavailability of drugs but also to reduce their adverse effects by means of the development of novel drug carrier systems. ${ }^{10}$ Polymeric nanoparticles are one of these carrier systems, which have been widely studied over the last two decades. They are submicrometric particles (mean size below $1 \mu \mathrm{m}$ ) and can be classified as nanospheres or nanocapsules. ${ }^{11}$ Nanospheres are composed by a matrix of polymer and nanocapsules are composed of an oily core surrounded by a thin polymer wall. ${ }^{12}$ Methods for the preparation of nanoparticles can start from either monomers (interfacial polymerization method) or from preformed polymers (nanoprecipitation and emulsification-diffusion methods). ${ }^{11,13}$ These carrier systems have showed potential use following topical (ocular, dermal) or systemic administration since the small size of the nanoparticles allow them to permeate through biological barriers. ${ }^{14}$ Polymeric nanoparticles have also been recently reported as an efficient coating material for the control of the drug release from microparticles. ${ }^{15-18}$

Some studies have been reported in the literature on the preparation of different kinds of dexamethasone-loaded

*e-mail: ruybeck@smail.ufsm.br nanoparticles. ${ }^{19-27}$ However, most of the studies used dexamethasone only as a lipophilic drug model.

In our previous study we developed dexamethasone-loaded nanospheres using poly ( $\varepsilon$-caprolactone) and poly (D,L-lactide) as biodegradable polymers. ${ }^{22}$ Both formulations were prepared by the nanoprecipitation method and presented good encapsulation efficiency (77.11 and $76.30 \%$, respectively), nanometric mean size (between 250 and $400 \mathrm{~nm}$ ), and absence of crystals of dexamethasone after their preparation. In addition, the importance of the dexamethasone-loaded nanospheres was evidenced by the fact that they significantly improved the in vivo anti-inflammatory activity of the nanoencapsulated drug compared to a commercial formulation. Although the pharmacological activity of dexamethasone was achieved, the formulations presented poor stability, showing a decline in the entrapment efficiency during the first month storage.

Recently, Gómez-Gaete and co-workers ${ }^{27}$ have reported the development of dexamethasone-loaded nanospheres prepared by a solvent emulsion-evaporation technique, which also presented a technological drawback to their development. Non-encapsulated dexamethasone crystals in the suspensions were visualized by optical microscopy just after the preparation. However, after several strategies the authors reported the preparation of suitable dexamethasone-loaded nanoparticles $(230 \mu \mathrm{g} / 100 \mathrm{mg}$ of PLGA 75:25) optimized for ocular delivery, using a mixture of dichloromethane-acetone as the organic solvent and $10 \mathrm{mg}$ of the drug.

Some works in the literature have pointed out the potential of the nanoencapsulation of dexamethasone to improve its topical or systemic anti-inflammatory activities, ${ }^{22,26,28,29}$ to allow its intravitreal injection, ${ }^{27}$ or to improve its ocular bioavailability. ${ }^{30}$ However, up to now there had been no reports in the literature devoted to optimize the encapsulation of dexamethasone in polymeric nanocapsules. Considering these aspects, the aim of this study was to develop and optimize a formulation of dexamethasone-loaded nanocapsules, 
which could be used for many purposes such as ocular administration or incorporation in semi-solids or solid formulations (topical or systemic administration, respectively). The following parameters were investigated for the optimization of the nanocapsule suspensions: dexamethasone content, the type of oily phase, and the type of hydrophilic (high HLB) and hydrophobic (low HLB) surfactant. Formulations were characterized by means of drug content, encapsulation efficiency, mean size, polydispersity index, $\mathrm{pH}$, and stability under storage. In addition, we evaluated the feasibility to use sunflower oil and sorbitan sesquioleate as alternative oily phase and surfactant, respectively, to prepare polymeric nanocapsule suspensions.

\section{EXPERIMENTAL}

\section{Materials}

Dexamethasone was obtained from Henrifarma (São Paulo, Brazil). Poly-e-caprolactone (PCL), poloxamer 188, sorbitan sesquioleate and sorbitan monooleate $\left(\right.$ Span $80^{\circledR}$ ) were acquired from Sigma (São Paulo, Brazil). Caprylic/capric triglyceride mixture was delivered from Brasquim (Porto Alegre, Brazil); sunflower oil and polysorbate 80 (Tween $80^{\circledR}$ ) were supplied by Henrifarma (São Paulo, Brazil). All others chemicals and solvents presented pharmaceutical grade and were used as received.

\section{Preparation and optimization of dexamethasone-loaded polymeric nanocapsule suspensions}

Nanocapsule (NC) suspensions were prepared $(n=3)$ by the interfacial deposition of preformed polymer method as described by Fessi and co-workers. ${ }^{31}$ Briefly, an organic solution consisted of dexamethasone, an oily phase $(3.3 \mathrm{~mL})$, a lipophilic surfactant $(0.776 \mathrm{~g})$, the polymer (PCL) $(1.0 \mathrm{~g})$ and acetone $(267.0 \mathrm{~mL})$ was added under moderate magnetic stirring to an aqueous solution $(533.0 \mathrm{~mL})$ containing a hydrophilic surfactant $(0.776 \mathrm{~g})$. The magnetic stirring was maintained for $10 \mathrm{~min}$. Then, the acetone was eliminated and the aqueous phase concentrated by evaporation

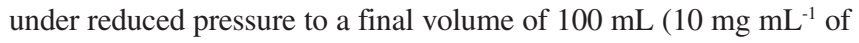
polymer). Blank NC suspensions were prepared, as control, using the same protocol described above, but omitting the presence of the drug. All formulations were prepared protected from the light and kept in the dark during all the time.

Formulations were optimized by the choice of dexamethasone initial drug content in the suspension $\left(0.25,0.50\right.$ or $\left.1.00 \mathrm{mg} \mathrm{mL}^{-1}\right)$, the type of the oily phase (caprylic/capric triglyceride mixture CCT or sunflower oil - SFO), the hydrophilic and lipophilic surfactant [polysorbate 80 (P80) or poloxamer 188 (P188) and sorbitan monooleate (SMO) or sorbitan sesquioleate (SSO), respectively]. Additionally, in order to evaluate the influence of the type of oily phase and the dexamethasone initial mass on the physicochemical characteristics of the suspensions we carried out a factorial design $2^{2}$, as showed in Table 1 .

Table 1. Factors and levels available in the factorial design

\begin{tabular}{ll}
\hline Factors & Levels \\
\hline A: Oily phase & $\begin{array}{l}\text { (-) Caprylic/capric triglycerides } \\
\text { mixture (CCT) } \\
(+) \text { Sunflower oil (SFO) }\end{array}$ \\
$\begin{array}{l}\text { B: Dexamethasone } \\
\text { initial concentration }\end{array}$ & $(-) 0.25 \mathrm{mg} \mathrm{mL}^{-1}$ \\
\hline
\end{tabular}

\section{Characterization of polymeric nanocapsule suspensions}

Determination of drug content and encapsulation efficiency

Drug content $(\mathrm{mg} / \mathrm{mL})$ was determined $(\mathrm{n}=3)$ after dissolution of nanocapsules in acetonitrile $(1 \mathrm{~mL}$ of suspension to $25 \mathrm{~mL}$ of acetonitrile) and assayed by high performance liquid chromatography - HPLC. The chromatographic system consisted of a Gemini RP-18 column (150 x $4.60 \mathrm{~mm}, 5 \mu \mathrm{m}$, Phenomenex, Torrance, USA) and a Shimadzu instrument (LC-10AVP Pump, UVVIS SPD-10AVP Module, Class-VP Software, Shimadzu, Tokyo, Japan). The mobile phase at a flow rate of $1.0 \mathrm{~mL} \mathrm{~min}^{-1}$ consisted of acetonitrile/water (45:55\% v/v). The volume injected was $20 \mu \mathrm{L}$ and dexamethasone was detected at $254 \mathrm{~nm} .{ }^{22,32}$ Validation of the HPLC assay demonstrated that this method was linear $\left(r^{2}=0.9997\right)$ in the range of $5-40 \mu \mathrm{g} \mathrm{mL}^{-1}$, precise (RSD: $1.33 \%$ for repeatability and $<1.70 \%$ for intermediate precision), and accurate (mean recovery: $101.58 \pm 0.39 \%$ ) within this range of concentration (5 $\left.40 \mu \mathrm{g} \mathrm{mL}^{-1}\right)$. The specificity was tested in presence of the nanoparticle adjuvants and demonstrated that these factors did not alter the dexamethasone assay. ${ }^{33}$

Free drug was determined in the clear supernatant following separation of nanocapsules from aqueous medium by a combined ultrafiltration-centrifugation technique (Ultrafree-MC ${ }^{\circledR}$ 10,000 MW, Millipore, Bedford, USA). Encapsulation efficiency (\%) was calculated by the difference between the total and free drug concentrations determined in the nanocapsule suspension (drug content) and in the ultrafiltrate, respectively, using the HPLC method described above.

\section{pH determination}

The $\mathrm{pH}$ values of suspensions were determined by immersion of the electrode directly in the suspension using a calibrated potentiometer (MPA-210 Model, MS-Tecnopon, São Paulo, Brazil), at room temperature.

\section{Particle size analysis and polydispersity indices}

The particle sizes and the polydispersity indices $(n=3)$ were measured by photon correlation spectroscopy after adequate dilution of an aliquot of the suspension in purified water (Zetasizer Nanoseries, Malvern Instruments, Worcestershire, UK).

\section{Optical microscopy}

Suspensions of nanocapsules were placed between glass slides and observed at magnifications of 100x and 400x with an Olympus optical microscope (Model CH30RF200, Olympus ${ }^{\circledR}$, Tokyo, Japan) equipped with a photographic camera (Model PM-C35B, Olympus ${ }^{\circledR}$, Tokyo, Japan).

\section{Stability studies}

Formulations were monitored following preparation until 2 months of storage by means of drug content and encapsulation efficiency, $\mathrm{pH}$ and particle size. NC suspensions were stored at room temperature and protected from light.

\section{Statistical analysis}

Formulations were prepared and analyzed in triplicate. Results are expressed as mean \pm SD (standard deviation). One-way analysis of variance (ANOVA) or two-way analysis of variance (ANOVA) were employed in the comparison of the experimental data. Posthoc multiple comparisons were done by Tukey's test. All analyses were run using the SigmaStat Statistical Program (Version 3.0, Jandel Scientific, USA). 


\section{RESULTS AND DISCUSSION}

In our previous report we showed an increase of the in vivo anti-inflammatory activity of dexamethasone-loaded nanospheres compared to a dexamethasone commercial solution, however, these systems showed a poor stability due to the drug leakage (surface desorption and/or diffusion to the aqueous medium). ${ }^{22}$ In order to overcome this drawback and to improve the stability of polymeric colloidal systems containing dexamethasone, this study aimed to develop dexamethasone-loaded polymeric nanocapsules, using a biodegradable polymer (poly- $\varepsilon$-caprolactone).

The method used to prepare the nanocapsule suspensions allowed to obtain polymeric colloidal systems, independently on the factors evaluated (dexamethasone content, type of oily phase and surfactants). However, the physicochemical characteristics, mainly the incorporation efficiency and stability, were clearly affected by these factors.

\section{Influence of dexamethasone initial concentration}

The influence of the initial concentration of dexamethasone was evaluated keeping all the other parameters constant. In order to study this influence, we prepared formulations $(n=3)$ containing the following dexamethasone content: $1.00 \mathrm{mg} \mathrm{mL}^{-1}, 0.50 \mathrm{mg}$ $\mathrm{mL}^{-1}, 0.25 \mathrm{mg} \mathrm{mL}^{-1}$, and $0.00 \mathrm{mg} \mathrm{mL}^{-1}$ (blank formulation). Table 2 shows the physicochemical characteristics of dexamethasone-loaded nanocapsules containing different theoretical drug contents.

Table 2. Physicochemical characteristics of dexamethasone-loaded NC prepared with CCT as oily phase: influence of the initial theoretical drug content (mean $\pm \mathrm{SD}$ )

\begin{tabular}{lccccc}
\hline $\begin{array}{l}\text { Theoretical } \\
\text { drug content } \\
\left(\mathrm{mg} \mathrm{mL}^{-1}\right)\end{array}$ & $\begin{array}{c}\text { Drug } \\
\text { content } \\
\left(\mathrm{mg} \mathrm{mL}^{-1}\right)\end{array}$ & $\begin{array}{c}\text { Encapsulation } \\
\text { efficiency } \\
(\%)\end{array}$ & $\begin{array}{c}\text { Mean } \\
\text { size } \\
(\mathrm{nm})\end{array}$ & PI & $\mathrm{pH}$ \\
\hline 1.00 & 0.68 & nd & 236 & 0.20 & 5.52 \\
& \pm 0.14 & & \pm 03 & \pm 01 & \pm 0.10 \\
0.50 & 0.51 & 89.56 & 253 & 0.23 & 5.36 \\
& \pm 0.06 & $\pm 1.21^{\mathrm{a}}$ & \pm 03 & \pm 05 & \pm 0.15 \\
0.25 & 0.27 & 82.24 & 229 & 0.14 & 5.49 \\
& \pm 0.03 & $\pm 3.91^{\mathrm{b}}$ & \pm 16 & \pm 05 & \pm 0.41 \\
0.00 & 0.00 & nd & 253 & 0.21 & 4.99 \\
& \pm 0.00 & & \pm 24 & \pm 07 & \pm 0.33 \\
\hline
\end{tabular}

Means, in column, with the same letter are not significantly different (ANOVA, $\mathrm{p} \leq 0.05$ ); nd: not determined (drug crystallization); PI: polydispersity index

As can be seen, the formulation prepared to contain $1.00 \mathrm{mg}$ $\mathrm{mL}^{-1}$ showed by the HPLC analysis only $68 \%$ of this theoretical concentration. This can be explained by the drug overloading followed by its crystallization in the external aqueous phase. This crystallization makes the system heterogeneous to the sampling and may decrease the drug content in the HPLC analysis. Similar results were observed during stability studies of diclofenac-loaded nanocapsules. ${ }^{34,35}$ In addition, to confirm our hypothesis of crystallization/precipitation we observed the suspension by optical microscopy. Dexamethasone crystals, which were observed in this suspension, were not observed in blank or in lower concentration formulations (not shown). It means that at this concentration a fraction of the active principle is not encapsulated. This crystallization may be explained by the full organic solvent evaporation, and the decrease in the dexamethasone solubility leading to its precipitation in the continuous aqueous phase, as demonstrated by previous reports. ${ }^{27,36}$

Regarding the formulations prepared at initial concentrations of 0.50 and $0.25 \mathrm{mg} \mathrm{mL}^{-1}$ of dexamethasone, both presented drug content according to the their theoretical value. However, the formulation containing $0.50 \mathrm{mg} \mathrm{mL}^{-1}$ presented higher encapsulation efficiency $(p<0.05)$ compared to the formulation containing 0.25 $\mathrm{mg} \mathrm{mL}^{-1}$ of dexamethasone. In relation to the other physicochemical characteristics, all formulations presented similar mean sizes (between 225 and $260 \mathrm{~nm}$ ), polydispersity indices below 0.25 , and $\mathrm{pH}$ in the acidic range. No difference was showed among the physicochemical characteristics of dexamethasone-loaded nanocapsules and unloaded-nanocapsules (blank formulation).

Comparing these results to our previous report, ${ }^{22}$ we can observe that the encapsulation efficiency of dexamethasone, at a concentration of $0.50 \mathrm{mg} \mathrm{mL}^{-1}$, was higher for nanocapsules $(89.56 \%)$ than for nanospheres $(77.11 \%)$. This fact may be explained by the presence of the oily phase in nanocapsules making them more hydrophobic than nanospheres. ${ }^{15}$

\section{Influence of the oily phase}

The type of oily phase used as core in preparation of polymeric nanocapsules could have a great influence on the particle mean size and polydispesity index due to the difference in its viscosity, hydrophobic characteristic and interfacial tension. ${ }^{11}$ In order to study the influence of the oily phase on the physicochemical characteristics of dexamethasone-loaded nanocapsules, as well as to evaluate the potential of using another oily phase (sunflower oil - SFO) to improve dexamethasone encapsulation, we carried out a $2^{2}$ factorial design, as shown in Table 1. Oily phase and the dexamethasone initial concentration were the factors evaluated. Caprylic/capric triglyceride mixture (CCT) has been widely used to prepare nanocapsule suspension $^{15,37,38}$ as medium-chain triglyceride. It contains $50-80 \%$ of caprylic acid and $20-50 \%$ of capric acid ${ }^{39}$. On the other hand, sunflower oil (SFO) is a long-chain triglycerides mixture, whose main components are oleic or linoleic acids, as unsatured fatty acids. ${ }^{40} \mathrm{Up}$ to now there had been no reports on the use of SFO to prepare polymeric nanocapsule suspensions. The results of the factorial design are presented in Table 3. Neither the oily phase nor the drug concentration showed a significant influence on the mean size and polydispersity index ( $p>0.05)$. All formulations presented mean size and polydispersity index below 280 $\mathrm{nm}$ and 0.25 , respectively, and $\mathrm{pH}$ in the acid range ( $\mathrm{pH} 5.0-6.0)$. On the other hand, dexamethasone initial concentration presented a significantly difference $(p<0.05)$ in relation to the encapsulation efficiency. The nanocapsule suspensions containing higher drug concentrations also presented the higher encapsulation efficiency, regardless the type of oily phase. This factorial design study allowed us to observe that the use of SFO instead of CCT did not improve dexamethasone encapsulation in the polymeric nanocapsules, showing the same result from both phases (around 90 and $80 \%$ at a concentration of 0.5 and $0.25 \mathrm{mg} \mathrm{mL}^{-1}$, respectively). On the other hand, the results showed the feasibility to use SFO as an oily phase in the preparation of polymeric nanocapsules, which presented nanometric mean size (189 - 230) and polydispersity index below 0.20. Nanocapsules containing SFO as oily phase could become interesting considering some properties of this oil like to accelerate the would healing process, ${ }^{41}$ to inhibit the increase of solid tumor growth, ${ }^{42}$ or to be added to many cosmetic formulations. ${ }^{43}$

Although the nanocapsule suspensions containing the lower initial dexamethasone content $\left(0.25 \mathrm{mg} \mathrm{mL}^{-1}\right)$ presented the lower encapsulation efficiency, we did not discard these formulations without evaluating their stability under storage (ambient temperature 
Table 3. Physicochemical characteristics of dexamethasone-loaded $\mathrm{NC}$ and the respective blank formulations: influence of the oily phase and the initial dexamethasone evaluated by a $2^{2}$ factorial design (mean $\pm \mathrm{SD}$ )

\begin{tabular}{lccccc}
\hline Oily phase & $\begin{array}{c}\text { Drug } \\
\text { content } \\
\left(\mathrm{mg} \mathrm{mL}^{-1}\right)\end{array}$ & $\begin{array}{c}\text { Encapsulation } \\
\text { efficiency } \\
(\%)\end{array}$ & $\begin{array}{c}\text { Mean } \\
\text { size } \\
(\mathrm{nm})\end{array}$ & PI & $\mathrm{pH}$ \\
\hline CCT & 0.51 & 89.56 & 253 & 0.23 & 5.36 \\
\pm 0.06 & $\pm 1.21^{\mathrm{a}}$ & \pm 03 & \pm 0.05 & \pm 0.15 \\
& 0.27 & 82.24 & 229 & 0.14 & 5.49 \\
& \pm 0.03 & $\pm 3.91^{\mathrm{b}}$ & \pm 16 & \pm 0.05 & \pm 0.41 \\
SFO & 0.51 & 87.50 & 229 & 0.15 & 5.99 \\
& \pm 0.06 & $\pm 0.17^{\mathrm{a}}$ & \pm 12 & \pm 0.01 & \pm 0.11 \\
& 0.27 & 78.07 & 227 & 0.17 & 5.72 \\
& \pm 0.01 & $\pm 1.88^{\mathrm{b}}$ & \pm 04 & \pm 0.03 & \pm 0.21 \\
\hline Blank formulations & TCM & 253 & 0.21 & 4.99 \\
& & & \pm 24 & \pm 0.07 & \pm 0.33 \\
& & SFO & 189 & 0.09 & 5.83 \\
& & & \pm 04 & \pm 0.04 & \pm 0.18 \\
\hline
\end{tabular}

Means, in column, with the same letter are not significantly different (Two-way ANOVA, Tukey's test, $\mathrm{p} \leq 0.05$ ); PI: polydispersity index

and protected from light).

Stability studies showed that at a concentration of $0.5 \mathrm{mg} \mathrm{mL}^{-1}$ only the formulation containing CCT as oily phase, showed an acceptable stability after 1 month of storage (Table 4), presenting high decrease in the total drug content ( 0.52 to $\left.0.27 \mathrm{mg} \mathrm{mL}^{-1}\right)$ after 2 months. On the other hand, formulations prepared with SFO presented a decrease in the drug content during the first month of storage. These decreases could be explained by the drug leakage (surface desorption and/or diffusion to the aqueous medium) and crystallization, as previously demonstrated for dexamethasone-loaded nanospheres. ${ }^{22}$ To confirm this hypothesis, we observed the suspensions by optical microscopy during the storage time and dexamethasone crystals could be detected. Blank formulations submitted to the stability studies did not show the presence of crystals, confirming the identity of the crystals observed in the drug-loaded nanocapsule suspensions as dexamethasone crystals (not shown). These alterations in the drug content during the storage time were also accompanied by an increase of the standard deviation in the mean size of particles. This increase was not observed for the blank formulation and could be related to the presence of crystals of dexamethasone in the continuous phase, as previously discussed. According to previous studies reported in the literature, this phenomenon could be attributed to the presence of nanocrystals, stabilized by surfactants, which start to grow and precipitate with time. ${ }^{11,37}$ Nevertheless, the analyses of mean size and polydispersity index of the formulations (Table 4) did not present any significant alteration during the storage time ( 2 months). Regarding the $\mathrm{pH}$ values, all formulations presented a decline in their values during the storage time (Table 4) if compared to the values obtained just after the preparation (Table 3), whose decline was also observed for blank formulations ( $\mathrm{pH} 4.20$ for both blank formulations - containing CCT or SFO - after 2 months of storage). This decline may be explained by the polymeric chains relaxation, which exposes a higher number of terminal carboxylic groups. ${ }^{34,44}$ In comparison, blank formulations presented stable mean sizes and polydispersity indices during the storage time $(250-270 \mathrm{~nm}$ and $0.21-0.26$, respectively for nanocapsules containing CCT; and $189-206 \mathrm{~nm}$ and $0.09-$
Table 4. Stability studies: physicochemical characteristics of dexamethasone-loaded $\mathrm{NC}\left(0.5 \mathrm{mg} \mathrm{mL}^{-1}\right.$ and $\left.0.25 \mathrm{mg} \mathrm{mL}^{-1}\right)$ after 1 and 2 months of storage at ambient temperature and protected from light (mean $\pm \mathrm{SD})$

\begin{tabular}{|c|c|c|c|c|c|}
\hline $\begin{array}{l}\text { Time } \\
\text { (months) }\end{array}$ & $\begin{array}{c}\text { Drug } \\
\text { content } \\
\left(\mathrm{mg} \mathrm{mL}^{-1}\right)\end{array}$ & $\begin{array}{c}\text { Encapsulation } \\
\text { efficiency } \\
(\%)\end{array}$ & $\begin{array}{c}\text { Mean } \\
\text { size } \\
(\mathrm{nm})\end{array}$ & PI & $\mathrm{pH}$ \\
\hline & & $0.5 \mathrm{mg} \mathrm{mL}^{-1}$ & & & \\
\hline \multicolumn{6}{|c|}{ Oily phase: CCT } \\
\hline 1 & $\begin{array}{c}0.52 \\
\pm 0.07\end{array}$ & $\begin{array}{l}90.79 \\
\pm 2.40\end{array}$ & $\begin{array}{r}247 \\
\pm 05\end{array}$ & $\begin{array}{c}0.23 \\
\pm 0.03\end{array}$ & $\begin{array}{c}4.19 \\
\pm 0.09\end{array}$ \\
\hline 2 & $\begin{array}{c}0.27 \\
\pm 0.06\end{array}$ & nd & $\begin{array}{r}278 \\
\pm 54\end{array}$ & $\begin{array}{c}0.29 \\
\pm 0.08\end{array}$ & $\begin{array}{c}4.09 \\
\pm 0.06\end{array}$ \\
\hline \multicolumn{6}{|c|}{ Oily phase: SFO } \\
\hline 1 & $\begin{array}{c}0.27 \\
\pm 0.04\end{array}$ & nd & $\begin{array}{r}220 \\
\pm 16\end{array}$ & $\begin{array}{c}0.18 \\
\pm 0.01\end{array}$ & $\begin{array}{c}4.70 \\
\pm 0.31\end{array}$ \\
\hline 2 & $\begin{array}{c}0.21 \\
\pm 0.06\end{array}$ & nd & $\begin{array}{r}252 \\
\pm 52\end{array}$ & $\begin{array}{c}0.21 \\
\pm 0.07\end{array}$ & $\begin{array}{c}3.96 \\
\pm 0.09\end{array}$ \\
\hline Oily phas & & $0.25 \mathrm{mg} \mathrm{mL}^{-1}$ & & & \\
\hline 1 & $\begin{array}{c}0.25 \\
\pm 0.03\end{array}$ & $\begin{array}{r}80.36 \\
\pm 2.24\end{array}$ & $\begin{array}{l}227 \\
\pm 20\end{array}$ & $\begin{array}{c}0.17 \\
\pm 0.05\end{array}$ & $\begin{array}{c}4.23 \\
\pm 0.10\end{array}$ \\
\hline 2 & $\begin{array}{c}0.22 \\
\pm 0.02\end{array}$ & $\begin{array}{c}61.41 \\
\pm 2.06\end{array}$ & $\begin{array}{r}278 \\
\pm 32\end{array}$ & $\begin{array}{c}0.17 \\
\pm 0.08\end{array}$ & $\begin{array}{c}3.91 \\
\pm 0.22\end{array}$ \\
\hline \multicolumn{6}{|c|}{ Oily phase: SFO } \\
\hline 1 & $\begin{array}{c}0.27 \\
\pm 0.05\end{array}$ & $\begin{array}{r}79.74 \\
\pm 7.32\end{array}$ & $\begin{array}{c}224 \\
\pm 05\end{array}$ & $\begin{array}{c}0.15 \\
\pm 0.02\end{array}$ & $\begin{array}{c}4.85 \\
\pm 0.30\end{array}$ \\
\hline 2 & $\begin{array}{c}0.24 \\
\pm 0.03\end{array}$ & $\begin{array}{l}81.25 \\
\pm 10.9\end{array}$ & $\begin{array}{r}280 \\
\pm 28\end{array}$ & $\begin{array}{c}0.19 \\
\pm 0.06\end{array}$ & $\begin{array}{c}3.98 \\
\pm 0.27\end{array}$ \\
\hline
\end{tabular}

nd: not determined (drug crystallization); PI: polydispersity index

0.12 , respectively for nanocapsules containing SFO). From these latter results, it can be observed that the use of SFO as an oily phase leads to colloidal suspensions presenting a smaller mean size (around 200 $\mathrm{nm}$ ) and lower polydispersity index (around 0.10 ).

Regarding stability studies on nanocapsule suspensions containing an initial drug content of $0.25 \mathrm{mg} \mathrm{mL}^{-1}$, the crystallization of the dexamethasone could not be prevented by lowering the drug concentration in the formulations (Table 4). Dexamethasone-loadednanocapsule $\left(0.25 \mathrm{mg} \mathrm{mL}^{-1}\right)$ prepared with the CCT presented an acceptable stability also after 1 month of storage like the formulation containing $0.50 \mathrm{mg} \mathrm{mL}^{-1}$ of drug. In relation to the suspensions prepared with SFO, although they presented a mean drug content during the storage time $\left(0.27 \pm 0.05\right.$ and $0.24 \pm 0.03 \mathrm{mg} \mathrm{mL}^{-1}$, after 1 and 2 months, respectively) around the theoretical value $(0.25$ $\mathrm{mg} \mathrm{mL}^{-1}$ ), these values presented a high variation (RSD:10 - 20\%) among the formulations $(n=3)$. This variation was also observed in the encapsulation efficiency values and may be related to the presence of drug crystals in the continuous phase. The mean size and polydispersity values of these formulations did not change during the storage time and all formulations presented a decline in their $\mathrm{pH}$ values during the storage time, as observed for the formulations containing $0.50 \mathrm{mg} \mathrm{mL}^{-1}$ of drug.

\section{Influence of the surfactants}

Nanocapsules can be stabilized by steric or electrostatic repulsion, depending on the nature of the surfactant. Surfactants are necessary to obtain small and stable oil droplets. This way, surfactants can affect the physicochemical properties of the 
nanoparticles such as size, drug loading, and drug stability. ${ }^{11,35,45,46}$ The surfactant influence on the physicochemical characteristics of the nanocapsule suspensions and the evaluation of this strategy as a tool to improve the stability of dexamethasone-loaded nanocapsules were studied. Thus, we chose the formulation containing $0.50 \mathrm{mg} \mathrm{mL}^{-1}$ of drug and prepared it with CCT as oily phase due to its better stability and higher drug content compared to the other formulations, as previously demonstrated.

The choice of the surfactants was made considering their different HLB (hydrophilic-lipophilic balance) values. High HLB surfactants used as hydrophilic surfactants were polysorbate 80 - P80 and poloxamer 188 - P188 (HLB of 15.0 and 29.0, respectively). Sorbitan monooleate (SMO) and sesquioleate (SSO) were used as lipophilic surfactants (HLB of 4.3 and 3.7, respectively). Dexamethasone-loaded nanocapsules and blank formulations were prepared using the following surfactant association: P80/SMO, P80/SSO, and P188/ SMO. The physicochemical characteristics obtained from these different formulations just after the preparation are shown in Table 5. The only formulations which presented drug content close to the theoretical value $\left(0.50 \mathrm{mg} \mathrm{mL}^{-1}\right)$ were the ones prepared with the association of P80/SMO and P80/SS0. The change in the HLB of the hydrophilic surfactant from 15 to 29 decreased the affinity of dexamethasone to the polymeric nanocapsule leading to an increase in its crystallization in the continuous phase. It can be explained by the higher solubilizing ability of surfactants presenting a high HLB value, which could dislocate the drug from the nanocapsule to the continuous medium followed by its precipitation. Regarding the change of the surfactant with low HLB value it was observed that the decrease in its HLB value from 4.3 to 3.7 (for SMO and SSO, respectively) resulted in a decrease in the mean size and in the polydispersity index of drug-loaded as well as of drug-unloaded formulations (Table 5). The influence of the type and concentration of surfactants in the formation of nanocapsules and in their mean size and polydispersity index were already reported in the literature. ${ }^{11,45,47,48}$ However, most of the studies demonstrated the influence of the hydrophilic surfactant. Alvarez-Román and coworkers ${ }^{11}$ showed an increase of the mean size of poly( $\varepsilon$-caprolactone) nanocapsules prepared in presence of poloxamer $188(\mathrm{HLB}=29)$ in relation to the same nanocapsules prepared in presence of polysorbate 85 (HLB = 11). On the other hand, Quintanar-Guerrero and coworkers $^{49}$ demonstrated a decrease in the mean size of polymeric nanocapsule prepared with polysorbate $80(\mathrm{HLB}=15)$ in relation to the nanocapsule suspension prepared with poloxamer 188 (HLB = 29). Moreover, Schaffazick and co-workers ${ }^{50}$ did not show any influence regarding the type of surfactant on the mean size or on the drug encapsulation of poly( $\varepsilon$-caprolactone) nanocapsules containing melatonin. In our studies we showed the influence of the HLB value of the hydrophilic and lipophilic surfactant on the drug loading efficiency and mean size, respectively.

Regarding the stability studies of the drug-loaded formulations prepared with different surfactant associations, only the formulation prepared with P80/SMO showed an acceptable stability after 1 month of storage (Table 6). The instability observed for the other formulations was related to the drug content (decrease or high variation among the batches) and consequently the encapsulation efficiency. As can be seen in Table 6, no changes were observed on the mean size or polydispersity of the suspensions. $\mathrm{pH}$ values decreased during the storage time for all formulations, as previously commented.

In order to confirm the decrease in the mean size of the nanocapsule as well as in the polydispersity index by the change in

Table 5. Physicochemical characteristics of dexamethasone-loaded NC and the respective blank formulations: influence of the hydrophilic (Polysorbate 80 - P80 or Poloxamer 188 - P188) and the hydrophobic surfactant (sorbitan monooleate - SMO or sorbitan sesquioleate $\mathrm{SSO})$. Mean $\pm \mathrm{SD}$

\begin{tabular}{|c|c|c|c|c|c|}
\hline $\begin{array}{l}\text { Surfactant } \\
\text { association }\end{array}$ & $\begin{array}{l}\text { Drug content } \\
\left(\mathrm{mg} \mathrm{mL} \mathrm{mL}^{-1}\right)\end{array}$ & $\begin{array}{l}\text { Encapsulation } \\
\text { efficiency }(\%)\end{array}$ & $\begin{array}{l}\text { Mean size } \\
\quad(\mathrm{nm})\end{array}$ & PI & $\mathrm{pH}$ \\
\hline P80/SMO & $0.51 \pm 0.06$ & $89.56 \pm 1.21$ & $253 \pm 03$ & $0.23 \pm 0.05$ & $5.36 \pm 0.15$ \\
\hline P188/SMO & $0.33 \pm 0.06$ & nd & $258 \pm 42$ & $0.17 \pm 0.08$ & $6.90 \pm 0.24$ \\
\hline P80/SSO & $0.46 \pm 0.03$ & $93.48 \pm 3.46$ & $212 \pm 07$ & $0.09 \pm 0.02$ & $7.47 \pm 0.19$ \\
\hline Blank & P80/SMO & & $253 \pm 24$ & $0.21 \pm 0.07$ & $4.99 \pm 0.33$ \\
\hline \multirow[t]{2}{*}{ formulations } & P188/SMO & & $251 \pm 15$ & $0.14 \pm 0.04$ & $7.17 \pm 0.23$ \\
\hline & P80/SSO & & $205 \pm 09$ & $0.11 \pm 0.01$ & $7.71 \pm 0.06$ \\
\hline
\end{tabular}

nd: not determined (drug crystallization); PI: polydispersity index

Table 6. Stability studies: physicochemical characteristics of dexamethasone-loaded NC prepared with different surfactant associations after 1 and 2 months of storage at ambient temperature and protected from light (mean \pm SD)

\begin{tabular}{|c|c|c|c|c|c|}
\hline $\begin{array}{l}\text { Time } \\
\text { (months) }\end{array}$ & $\begin{array}{l}\text { Drug content } \\
\left(\mathrm{mg} \mathrm{mL} \mathrm{mL}^{-1}\right)\end{array}$ & $\begin{array}{l}\text { Encapsulation } \\
\text { efficiency }(\%)\end{array}$ & $\begin{array}{l}\text { Mean size } \\
\quad(\mathrm{nm})\end{array}$ & PI & $\mathrm{pH}$ \\
\hline \multicolumn{6}{|c|}{ Surfactants: P80/SMO } \\
\hline 1 & $0.52 \pm 0.07$ & $90.79 \pm 2.40$ & $247 \pm 05$ & $0.23 \pm 0.03$ & $4.19 \pm 0.09$ \\
\hline 2 & $0.27 \pm 0.06$ & nd & $278 \pm 54$ & $0.29 \pm 0.08$ & $4.09 \pm 0.06$ \\
\hline \multicolumn{6}{|c|}{ Surfactants: P188/SMO } \\
\hline 1 & $0.54 \pm 0.19$ & nd & $260 \pm 39$ & $0.18 \pm 0.09$ & $4.90 \pm 0.50$ \\
\hline 2 & $0.58 \pm 0.35$ & nd & $261 \pm 39$ & $0.17 \pm 0.08$ & $4.65 \pm 0.45$ \\
\hline \multicolumn{6}{|c|}{ Surfactants: P80/SSO } \\
\hline 1 & $0.45 \pm 0.16$ & nd & $230 \pm 23$ & $0.18 \pm 0.07$ & $6.28 \pm 0.12$ \\
\hline 2 & $0.33 \pm 0.09$ & nd & $249 \pm 51$ & $0.21 \pm 0.10$ & $5.89 \pm 0.49$ \\
\hline
\end{tabular}

nd: not determined (drug crystallization); PI: polydispersity index 
the low HLB value surfactant and the instability of the suspensions due to presence of the drug we carried out the stability study with blank formulations. As observed for the drug-loaded formulations, all blank formulations showed a decrease in their $\mathrm{pH}$ values after 2 months $(4.09 \pm 0.06,4.65 \pm 0.45$ and $5.89 \pm 0.49$ for formulations containing the surfactant association P80/SMO, P188/SMO and P80/SS0, respectively). The use of the lipophilic surfactant with lowest HLB value (SSO) to prepare blank formulations led to the preparation of formulations presenting the lowest values of mean size and polydispersity index after the storage time $(211 \pm 16 \mathrm{~nm}$, $0.14 \pm 0.03$, respectively, after 2 months) compared to the suspension prepared with SMO as surfactant (P80/SMO: $252 \pm 21$ and $0.26 \pm 0.04$; P188/SMO: $254 \pm 23$ and $0.13 \pm 0.04$, respectively, after 2 months). The particle size and polydispersity index characteristics remained similar during all the storage time for the blank formulations. From these results, the strong influence of HLB of the surfactant on the mean size and polydispersity index of the suspensions could be clearly observed. This study is the first report on the use of sorbitan sesquioleate as a stabilizer agent for polymeric nanocapsules and showed its good efficiency to form nanocapsules with narrow diameter distribution.

\section{CONCLUSION}

This work showed the technological feasibility to prepare dexamethasone-loaded polymeric nanocapsules at a concentration of $0.5 \mathrm{mg} \mathrm{mL}^{-1}$, which presented encapsulation efficiency close to $90 \%$ and nanometric particle size. The choice of the oily phase and the surfactant association (hydrophilic/lipophilic surfactant) was fundamental to improve the stability of these formulations. The use of caprylic/capric triglyceride mixture as oily phase and the association of polysorbate and sorbitan monooleate as surfactants led to more stable formulations. In addition, the use of sunflower oil and sorbitan sesquioleate was showed for the first time as alternatives of oily phase and lipophilic surfactant, respectively, to prepare nanocapsules with good colloidal properties (low mean size and narrow size distribution). Studies are in progress to incorporate these dexamethasone-loaded nanocapsules in solid dosage forms as well as in semi-solid formulations, as alternatives to systemic or topical delivery of dexamethasone.

\section{ACKNOWLEDGEMENTS}

M. C. Fontana thanks CNPq for her scholarship. The authors thank the financial support of FAPERGS and Rede Nanocosméticos/CNPq.

\section{REFERENCES}

1. Schimmer, B. P.; Parker, K. L. Em As bases farmacológicas da terapêutica; Gilman, A. G.; Hardman, J. G.; Limbird, L. E., eds.; Guanabara-Koogan: Rio de Janeiro, 2003, p. 1241-1262.

2. Munoz-Fernandez, S.; Martin-Mola, E.; Best Pract. Res Clin. Rheumatol. 2006, 20, 487.

3. Shoji, J.; Sakimoto, T.; Muromoto, K.; Inada, N.; S, Mitsuru., R.; Jpn. J. Ophthalmol. 2005, 49, 205.

4. Yülek, F.; Ozdek, S.; Gurelik, G.; Hasanreisoglu, B.; Acta Ophthalmol. Scand. 2006, 84, 319.

5. Matsumoto, K.; Mizukoshi, K.; Oyobikawa, M.; Ohshima, H.; Sakai, Y.; Tagami, H.; Skin Res. Technol. 2005, 11, 209.

6. Trautmann, A.; Akdis, M.; Schmid-Grendelmeier, P.; Disch, R.; Bröcker, E. B.; Blaser, K.; Akdis, A. C.; J. Allergy Clin. Immunol. 2001, 108, 839.

7. Levin, C.; Maibach, H. I.; Dermatologie in Beruf und Umwelt 2000, 48, 179.

8. Valencia, I. C.; Kerdel, F. A. Em Fitzpatrick's Dermatology in General Medicine; Freedberg, I. M.; Eisen, A. Z.; Wolff, K.; Austen, K. F.;
Goldsmith, L. A.; Katz, S., eds.; McGraw-Hill Professional: New York, 2003, p. $2585-2595$.

9. Zampieri, N.; Corroppolo, M.; Zuin, V.; Bianchi, S.; Camoglio, F. S.; Pediatr. Surg. Int. 2007, 23, 331.

10. Kidane, A.; Bhatt, P.; Curr. Opin. Chem. Biol. 2005, 9, 347.

11. Schaffazick, S. R.; Freitas, L. L.; Pohlmann, A. R.; Guterres, S. S.; Quim. Nova 2003, 25, 726.

12. Barratt, G.; Cell Mol. Life Sci. 2003, 60, 21.

13. Couvreur, P.; Barratt, G.; Fattal, E.; Legrand, P.; Vauthier, C.; Crit. Rev. Ther. Drug 2002, 19, 99.

14. Alonso, M. J.; Biomed. Pharmacother. 2004, 58,168.

15. Beck, R. C. R.; Pohlmann, A. R.; Guterres, S. S.; J. Microencapsulation 2004, 21, 499

16. Beck, R. C. R.; Pohlmann, A. R.; Benvenutti, E. V.; Dalla Costa, T.; Guterres, S. S.; J. Braz. Chem. Soc. 2005, 16, 1233.

17. Beck, R. C. R.; Hass, S. E.; Guterres, S. S.; Re, M. I.; Benvenutti, E. V.; Pohlamnn, A. R.; Quim. Nova 2006, 29, 990.

18. Beck, R. C. R.; Pohlmann, A. R.; Hoffmeister, C.; Gallas, M. R.; Collnot, E.; Schaefer, U. F.; Guterres, S. S.; Lehr, C. M.; Eur. J. Pharm. Biopharm. 2007, 67, 18.

19. Fessi, H.; Puisieux, F.; Devissaguet, J. P.; Ammoury, N.; Benita, S.; Int. J. Pharm. 1989, 55, R1.

20. Seijo, B.; Fattal, E.; Roblot-Treupel, L.; Couvreur, P.; Int. J. Pharm. 1990, $62,1$.

21. Song, C. X.; Labhasetwar, V.; Murphy, H.; Qu, X.; Humphrey, W. R.; Shebuski, R. J.; Levy, R. J.; J. Controlled Release 1997, 43, 197.

22. Beck, R. C. R.; Guterres, S. S.; Freddo, R. J.; Michalowski, C. B.; Barcellos, I.; Funck, J. A. B.; Acta Farm. Bonaerense 2003, 22, 11.

23. Kallinteri, P.; Higgins, S.; Hutcheon, G. A.; St. Pourcain, C. B.; Garnett, M. C.; Biomacromolecules 2005, 6, 1885.

24. Zahr, A. S.; De Villiers, M.; Pishko, M. V.; Langmuir 2005, 21, 403.

25. Heffernan, M. J.; Murthy, N.; Bioconjugate Chem. 2005, 16, 1340.

26. Seki, J.; Sonoke, S.; Saheki, A.; Fukui, H.; Sasaki, H.; Mayumi, T.; Int. J. Pharm. 2004, 273, 75.

27. Gomez-Gaete; C., Tsapis, N.; Besnard, M.; Bochot, A.; Fattal, E.; Int. J. Pharm. 2007, 331, 153.

28. Cevc, G.; Adv. Drug Delivery Rev. 2004, 56, 675.

29. Cevc, G.; Blume, G.; Biochim. Biophys. Acta 2004, 1663, 61.

30. Fialho, S. L.; da Silva-Cunha, A.; Clin. Experiment Ophthalmol. 2004, 32 , 626.

31. Fessi, H.; Puisieux, F.; Devissaguet, J. P.; EP 0274961 A1, 1988.

32. Beck, R. C. R.; Acta Farm. Bonaerense 2001, $20,127$.

33. The United States Pharmacopoeia/The National Formulary; United States, Pharmacopoeial Convention Inc.: Rockville, USA, 2004

34. Schaffazick, S. R.; Pohlmann, A. R.; Freitas, L. L.; Guterres, S. S.; Acta Farm. Bonaerense 2002, 21, 99.

35. Müller, C. R.; Haas, S. E.; Bassani, V. L.; Guterres, S. S.; Peralba, M. C. R.; Pohlmann, A. R.; Quim. Nova 2004, 27, 555.

36. Layre, A. M.; Gref, R.; Richard, J.; Requier, D.; Chacun, H.; Appel, M.; Domb, A. J.; Couvreur, P.; Int. J. Pharm. 2005, 298, 323.

37. Guterres, S. S.; Fessi, H.; Barratt, G.; Puisieux, F.; Devissaguet, J. P.; Int. J. Pharm. 1995, 113, 57.

38. Teixeira, M.; Alonso, M. J.; Pinto, M. M. M.; Barbosa, C. M.; Eur. J. Pharm. Biopharm. 2005, 59, 491.

39. Rowe, R. C.; Sheskey, P. J.; Weller, P. J.; Pharmaceutical Excipients 2001, Pharmaceutical Press: London, 2001.

40. Carvalho, I. S.; Miranda, I.; Pereira, H.; Ind. Crop. Prod. 2006, 24, 75.

41. Marques, S. R.; Peixoto, C. A.; Messias, J. B.; Albuquerque, A. R.; da Silva Junior, V. A.; Acta Cir. Bras. 2004, 19, 196.

42. Silva, L. A.; Nascimento, K. A.; Maciel, M. C.; Pinheiro, M. T.; Sousa, P. R.; Ferreira, S. C.; Azevedo, A. P.; Guerra, R. N.; Nascimento, F. R.; Chemotherapy 2006, 52, 91 .

43. Souto, E. B.; Gohla, S. H.; Muller, R. H.; Pharmazie 2005, 60, 671.

44. Lopes, E.; Pohlmann, A. R.; Bassani, V. L.; Guterres, S. S.; Pharmazie 2000, 55, 527.

45. Magenheim, B.; Benita, S.; STP Pharma Sci. 1991, 1, 221

46. Losa, C.; Marchal-Heussler, L.; Orallo, F.; Vila Jato, J. L.; Alonso, M. J.; Pharm. Res. 1993, 10, 80.

47. Chasteigner, S.; Fessi, H.; Devissaguet, J. P.; Puisieux, F.; Drug Dev. Res. 1996, 38,125

48. Alvarez-Roman, R.; Barre, G.; Guy, R. H.; Fessi, H.; Eur. J. Pharm. Biopharm. 2001, 52, 191.

49. Quintanar-Guerrero, D.; Fessi, H.; Allémann, E.; Doelker, E.; Int. J. Pharm. 1996, 143, 133.

50. Schaffazick, S. R.; Pohlmann, A. R.; Mezzalira, G.; Guterres, S. S.; J. Braz. Chem. Soc. 2006, 17, 562. 